\title{
Characteristics and prognosis of mucinous gastric carcinoma
}

\author{
TARO ISOBE, KOUSUKE HASHIMOTO, JUNYA KIZAKI, SATORU MATONO, \\ NAOTAKA MURAKAMI, TETSUSHI KINUGASA, KEISHIRO AOYAGI and YOSHITO AKAGI
}

Department of Surgery, Kurume University School of Medicine, Fukuoka 830-0011, Japan

Received June 26, 2014; Accepted October 8, 2014

DOI: $10.3892 /$ mco.2014.447

\begin{abstract}
Mucinous gastric carcinoma (MGC) is a rare histological subtype of undifferentiated gastric carcinoma, accounting for $\sim 2.6-6.6 \%$ of all gastric cancer cases. The clinicopathological characteristics and prognosis of MGC are controversial. The present study aimed to determine the clinicopathological characteristics and prognosis of patients with MGC. We retrospectively compared the characteristics and postoperative survival of 70 patients with MGC and 2,492 non-MGC (NMGC) cases who underwent surgical resection between 1990 and 2010. MGC was characterised by larger tumor size, macroscopic Borrmann type 2 and 3, T4 invasion of the gastric wall, positive N2 and N3 lymph node metastasis, positive lymphatic vessel invasion, positive venous invasion, peritoneal metastasis and advanced tumor stage III and IV. The prognosis of MGC patients was worse compared to that of NMGC patients, as the former group consisted of more advanced-stage cases. When patients with similar disease stages were compared, the incidence of peritoneal metastasis was significantly higher among MGC patients. However, hepatic metastasis was found significantly more often in NMGC patients. Otherwise, the prognosis of MGC and NMGC patients with similar disease stages was not significantly different. Therefore, our findings indicated that, although MGC is more rare and mostly detected at an advanced stage, the diagnosis of the mucinous histological subtype was not an independent prognostic factor.
\end{abstract}

\section{Introduction}

Gastric cancer is one of the most common causes of cancer-related mortality. One million new cases are diagnosed annually, accounting for 700,000 mortalities worldwide $(1,2)$. Undifferentiated gastric carcinomas are generally associated with a worse prognosis (3). Mucinous gastric carcinoma (MGC) is a rare histological subtype of undifferentiated

Correspondence to: Dr Taro Isobe, Department of Surgery, Kurume University School of Medicine, 67 Asahi-machi, Kurume, Fukuoka 830-0011, Japan

E-mail: taro_isobe@yahoo.co.jp

Key words: gastric cancer, mucinous gastric carcinoma gastric carcinoma, accounting for 2.6-6.6\% of all gastric cancer cases (4-8). The available literature on MGC is currently limited, mostly due to its rarity. Several previous studies have suggested that the prognosis of MGC patients is poor $(5,9,10)$, whereas others reported no differences in characteristics and prognosis between MGC and non-MGC (NMGC) cases $(7,11)$. Thus, the clinicopathological characteristics and prognosis of MGC following surgical resection remain controversial. The present study aimed to determine the clinicopathological characteristics and postoperative survival of MGC patients.

\section{Materials and methods}

Patients. We identified 2,706 patients who underwent surgical treatment for gastric cancer between 1990 and 2010 at the Department of Surgery, Kurume University School of Medicine (Fukuoka, Japan). Patients with gastric cancer in the residual stomach following a prior gastrectomy and those undergoing surgery after an endoscopic procedure were excluded. Microscopic examination of hematoxylin and eosin-stained tissue sections from formalin-fixed, paraffin-embedded surgical specimens revealed 70 cases of MGC and 2,492 of NMGC. MGC was defined by the World Health Organization as an adenocarcinoma, in which over half of the tumor area contained extracellular mucin pools (12).

The study design and procedures were in accordance with the Declaration of Helsinki and were approved by the Ethics Committee of Kurume University (no. 14057). All the participants provided written informed consent.

Clinicopathological characteristics. We retrospectively reviewed the patients' medical charts, surgical records and histopathological reports to collect information on their clinicopathological characteristics, including age, gender, tumor size, tumor location, macroscopic type, histological type, depth of invasion, lymph node metastasis, lymphovascular invasion, distant metastasis and tumor stage. The tumor characteristics were defined according to the Japanese Classification of Gastric Carcinoma (3rd English edition) (13). All the patients were regularly followed up according to our standard protocol (at least every 3 months for 5 years), which included tumor marker studies, gastrointestinal endoscopy, ultrasonography and computed tomography.

Statistical analyses. The clinicopathological factors were compared using the Fisher's exact test or the Pearson's $\chi^{2}$ test, 
Table I. Comparison of clinicopathological characteristics between MGC and NMGC patients.

\begin{tabular}{|c|c|c|c|c|c|}
\hline \multirow[b]{2}{*}{ Characteristics } & \multicolumn{2}{|c|}{$\operatorname{MGC}(\mathrm{n}=70)$} & \multicolumn{2}{|c|}{$\operatorname{NMGC}(n=2,492)$} & \multirow[b]{2}{*}{ P-value } \\
\hline & No. & $\%$ & No. & $\%$ & \\
\hline Age, years (mean $\pm S D)$ & \multicolumn{2}{|c|}{$66.8 \pm 11.0$} & \multicolumn{2}{|c|}{$65.0 \pm 11.4$} & 0.207 \\
\hline Gender & & & & & 0.583 \\
\hline Male & 50 & 71.4 & 1,703 & 68.3 & \\
\hline Female & 20 & 28.6 & 789 & 31.7 & \\
\hline Tumor size, $\mathrm{mm}($ mean $\pm \mathrm{SD})$ & \multicolumn{2}{|c|}{$83.0 \pm 41.4$} & \multicolumn{2}{|c|}{$54.9 \pm 39.7$} & $<0.001^{\mathrm{a}}$ \\
\hline Tumor location & & & & & 0.345 \\
\hline Upper & 12 & 17.1 & 486 & 19.5 & \\
\hline Middle & 16 & 22.9 & 738 & 29.6 & \\
\hline Lower & 33 & 47.1 & 1,063 & 42.7 & \\
\hline Whole & 9 & 12.9 & 205 & 8.2 & \\
\hline Macroscopic type & & & & & $<0.001^{\mathrm{a}}$ \\
\hline Borrmann 0 & 7 & 10.0 & 1,377 & 55.3 & \\
\hline Borrmann 1 & 5 & 7.1 & 52 & 2.1 & \\
\hline Borrmann 2 & 18 & 25.7 & 294 & 11.8 & \\
\hline Borrmann 3 & 31 & 44.3 & 416 & 16.7 & \\
\hline Borrmann 4 & 4 & 5.8 & 173 & 6.9 & \\
\hline Borrmann 5 & 5 & 7.1 & 180 & 7.2 & \\
\hline Depth of invasion & & & & & $<0.001^{\mathrm{a}}$ \\
\hline $\mathrm{T} 1$ & 6 & 8.6 & 1,373 & 55.1 & \\
\hline $\mathrm{T} 2$ & 8 & 11.4 & 191 & 7.7 & \\
\hline $\mathrm{T} 3$ & 5 & 7.1 & 117 & 4.7 & \\
\hline $\mathrm{T} 4$ & 51 & 72.9 & 811 & 32.5 & \\
\hline Lymph node metastasis & & & & & $<0.001^{\mathrm{a}}$ \\
\hline No & 19 & 27.1 & 1,610 & 64.6 & \\
\hline N1 & 7 & 10.0 & 246 & 9.9 & \\
\hline $\mathrm{N} 2$ & 13 & 18.6 & 220 & 8.8 & \\
\hline N3 & 31 & 44.3 & 416 & 16.7 & \\
\hline Lymphatic invasion & 70 & 100.0 & 1,569 & 63.0 & $<0.001^{\mathrm{a}}$ \\
\hline Venous invasion & 51 & 72.9 & 986 & 39.6 & $<0.001^{\mathrm{a}}$ \\
\hline Peritoneal metastasis & 17 & 24.3 & 153 & 6.1 & $<0.001^{\mathrm{a}}$ \\
\hline Hepatic metastasis & 0 & 0.0 & 75 & 3.0 & 0.141 \\
\hline Stage & & & & & $<0.001^{\mathrm{a}}$ \\
\hline I & 9 & 12.9 & 1,448 & 58.1 & \\
\hline II & 14 & 20.0 & 312 & 12.5 & \\
\hline III & 19 & 27.1 & 388 & 15.6 & \\
\hline IV & 28 & 40.0 & 344 & 13.8 & \\
\hline
\end{tabular}



as appropriate. Disease-specific survival rates were analyzed using the Kaplan-Meier method and comparisons between groups were assessed by the log-rank test. In the multivariate analysis, the Cox proportional hazards model was used to identify independent prognostic factors. A P-value of $<0.05$ was considered to indicate statistically significant differences. All the statistical analyses were performed using JMP 10 software (SAS Institute, Inc., Cary, NC, USA).

\section{Results}

Clinicopathological characteristics. Table I summarizes the characteristics of all 2,562 patients included in the present study. Of the 70 MGC cases (2.7\% of all resected gastric cancer cases in this study), only $6(8.6 \%)$ were early-stage, whereas the remaining 64 patients (91.4\%) had advanced-stage disease. When compared to NMGC tumors, MGC tumors 
Table II. Comparison of clinicopathological characteristics between stage III and IV MGC and NMGC patients.

\begin{tabular}{|c|c|c|c|c|c|}
\hline \multirow[b]{2}{*}{ Characteristics } & \multicolumn{2}{|c|}{$\operatorname{MGC}(n=47)$} & \multicolumn{2}{|c|}{ NMGC (n=732) } & \multirow[b]{2}{*}{ P-value } \\
\hline & No. & $\%$ & No. & $\%$ & \\
\hline Age, years (mean \pm SD) & & & & & 0.986 \\
\hline Gender & & & & & 0.912 \\
\hline Male & 32 & 68.1 & 504 & 68.9 & \\
\hline Female & 15 & 31.9 & 228 & 31.1 & \\
\hline Tumor size, mm (mean \pm SD) & & & & & 0.343 \\
\hline Tumor location & & & & & 0.153 \\
\hline Upper & 7 & 14.9 & 182 & 24.9 & \\
\hline Middle & 7 & 14.9 & 121 & 16.5 & \\
\hline Lower & 24 & 51.1 & 258 & 35.2 & \\
\hline Whole & 9 & 19.1 & 171 & 23.4 & \\
\hline Macroscopic type & & & & & 0.364 \\
\hline Borrmann 0 & 1 & 2.1 & 6 & 0.8 & \\
\hline Borrmann 1 & 1 & 2.1 & 24 & 3.3 & \\
\hline Borrmann 2 & 13 & 27.7 & 171 & 23.3 & \\
\hline Borrmann 3 & 25 & 53.2 & 324 & 44.3 & \\
\hline Borrmann 4 & 4 & 8.5 & 149 & 20.4 & \\
\hline Borrmann 5 & 3 & 6.4 & 58 & 7.9 & \\
\hline Depth of invasion & & & & & 0.928 \\
\hline $\mathrm{T} 1$ & 0 & 0.0 & 5 & 0.7 & \\
\hline $\mathrm{T} 2$ & 1 & 2.1 & 21 & 2.9 & \\
\hline $\mathrm{T} 3$ & 3 & 6.4 & 41 & 5.6 & \\
\hline $\mathrm{T} 4$ & 43 & 91.5 & 665 & 90.8 & \\
\hline Lymph node metastasis & & & & & 0.411 \\
\hline No & 1 & 2.1 & 26 & 3.5 & \\
\hline N1 & 4 & 8.5 & 122 & 16.7 & \\
\hline N2 & 11 & 23.4 & 175 & 23.9 & \\
\hline N3 & 31 & 66.0 & 409 & 55.9 & \\
\hline Lymphatic invasion & 47 & 100.0 & 731 & 99.9 & 0.800 \\
\hline Venous invasion & 41 & 87.2 & 656 & 89.6 & 0.606 \\
\hline Peritoneal metastasis & 17 & 36.2 & 153 & 20.9 & $0.014^{\mathrm{a}}$ \\
\hline Hepatic metastasis & 0 & 0.0 & 75 & 10.3 & $0.021^{\mathrm{a}}$ \\
\hline Stage & & & & & 0.094 \\
\hline III & 19 & 40.4 & 388 & 53.0 & \\
\hline IV & 28 & 59.6 & 344 & 47.0 & \\
\hline
\end{tabular}

aStatistically significant. MGC, mucinous gastric carcinoma; NMGC, non-MGC; SD, standard deviation.

were larger in size (83.0 vs. $54.9 \mathrm{~mm})$, were more frequently Borrmann type 2 and 3 (70.0 vs. 28.5\%), presented with a higher rate of T4 invasion of the gastric wall (72.9 vs. 32.5\%), positive $\mathrm{N} 2$ and N3 lymph node metastasis (62.9 vs. $25.5 \%$ ), positive lymphatic vessel invasion (100.0 vs. $63.0 \%$ ), positive venous invasion (72.9 vs. $39.6 \%$ ), peritoneal metastasis (24.3 vs. $6.1 \%$ ) and advanced tumor stages III and IV (67.1 vs. 29.4\%). The clinicopathological characteristics of stage III and IV MGC and NMGC were also compared (Table II), revealing significant differences only in the peritoneal and hepatic metastasis status. MGC patients experienced a significantly higher incidence of peritoneal metastasis compared to NMGC patients ( 36.2 vs. $20.9 \%$, respectively; $\mathrm{P}=0.014$ ), whereas hepatic metastasis was more frequently encountered in NMGC patients ( 0.0 vs. $10.3 \%$; $\mathrm{P}=0.021)$.

Postoperative survival. The median follow-up period was 61.0 months (range, 1-228 months). Fig. 1 shows the postoperative disease-specific survival curves of all the patients. The disease-specific survival rate of MGC patients was 


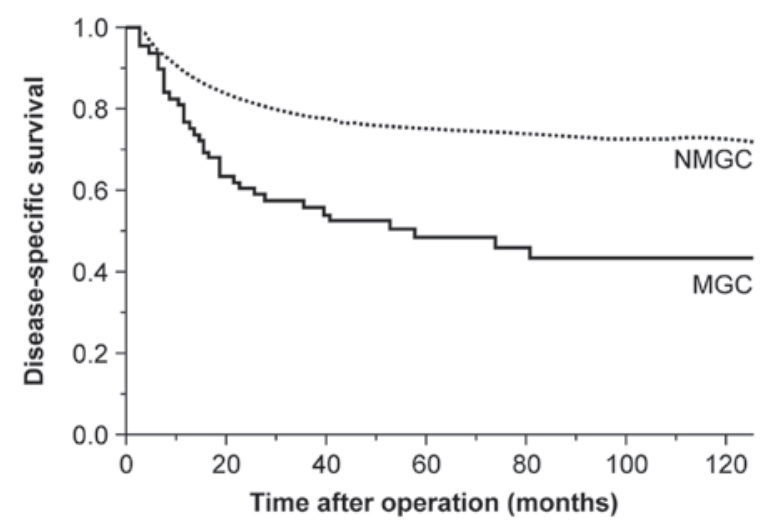

Figure 1. Disease-specific survival of all the patients. The survival of mucinous gastric carcinoma (MGC) patients was significantly lower compared to that of non-MGC (NMGC) patients $(\mathrm{P}<0.001)$. The 5- and 10-year survival rates of MGC patients were 48.7 and $75.2 \%$, respectively, whereas the corresponding rates for NMGC patients were 43.6 and $72.9 \%$, respectively. MGC, solid line; NMGC, dotted line.


Figure 2. Five- and 10-year survival rates according to disease stage. There were no significant differences in 5- and 10-year survival rates between mucinous gastric carcinoma (MGC) and non-MGC (NMGC) patients. MGC, solid line; NMGC, dotted line.

Table III. Comparison of 5- and 10-year survival by disease stage between MGC and NMGC patients.

\begin{tabular}{lcccccc}
\hline & \multicolumn{2}{c}{ MGC $(\mathrm{n}=70)$} & & \multicolumn{2}{c}{ NMGC $(\mathrm{n}=2,492)$} & \\
\cline { 2 - 3 } Stage & $\begin{array}{c}5 \text {-year } \\
(\%)\end{array}$ & $\begin{array}{c}10 \text {-year } \\
(\%)\end{array}$ & & $\begin{array}{c}5 \text {-year } \\
(\%)\end{array}$ & $\begin{array}{c}10 \text {-year } \\
(\%)\end{array}$ & P-value \\
\hline I & 100.0 & 100.0 & & 98.5 & 96.9 & 0.690 \\
II & 85.1 & 85.1 & & 81.1 & 78.5 & 0.968 \\
III & 53.2 & 45.6 & & 44.0 & 39.1 & 0.105 \\
IV & 14.3 & 9.5 & & 6.4 & 4.1 & 0.386 \\
\hline
\end{tabular}

MGC, mucinous gastric carcinoma; NMGC, non-MGC. significantly lower compared to that of NMGC patients $(\mathrm{P}<0.001)$. The 5- and 10-year survival rates of MGC patients were 48.7 and $75.2 \%$, respectively, whereas the corresponding rates for NMGC patients were 43.6 and $72.9 \%$, respectively. However, when survival was compared between MGC and NMGC patients according to disease stage, no significant differences in 5- and 10-year survival rates were observed between the two groups (Fig. 2 and Table III).

Multivariate analysis of prognostic factors. The univariate analysis revealed that tumor size, macroscopic type, depth of invasion, lymph node metastasis, lymphatic vessel invasion, venous invasion and peritoneal metastasis were statistically predictive of 5 -year disease-free survival in 
Table IV. Univariate and multivariate analyses of prognostic factors for MGC patients.

\begin{tabular}{|c|c|c|c|c|c|c|}
\hline \multirow[b]{2}{*}{ Factors } & \multicolumn{3}{|c|}{ Univariate analysis } & \multicolumn{3}{|c|}{ Multivariate analysis } \\
\hline & $\begin{array}{c}\text { No. } \\
(\mathrm{n}=70)\end{array}$ & $\begin{array}{l}\text { 5-year disease-free } \\
\text { survival rate }(\%)\end{array}$ & P-value & $\begin{array}{l}\text { Odds } \\
\text { ratio }\end{array}$ & $95 \% \mathrm{CI}$ & P-value \\
\hline Age (years) & & & 0.870 & & & \\
\hline$\geq 65$ & 47 & 45.2 & & & & \\
\hline$<65$ & 23 & 52.2 & & & & \\
\hline Gender & & & 0.291 & & & \\
\hline Male & 50 & 50.7 & & & & \\
\hline Female & 20 & 43.8 & & & & \\
\hline Tumor size (mm) & & & $<0.001^{\mathrm{a}}$ & 1.15 & $0.48-2.98$ & 0.755 \\
\hline$\geq 80$ & 35 & 28.4 & & & & \\
\hline$<80$ & 35 & 70.8 & & & & \\
\hline Tumor location $(\mathrm{n}=61)$ & & & 0.803 & & & \\
\hline Lower & 33 & 52.9 & & & & \\
\hline Middle, upper & 28 & 56.9 & & & & \\
\hline Macroscopic type $(n=58)$ & & & $0.014^{\mathrm{a}}$ & 1.65 & $0.74-4.09$ & 0.231 \\
\hline Borrmann 3, 4 & 35 & 30.4 & & & & \\
\hline Borrmann 1, 2 & 23 & 58.4 & & & & \\
\hline Depth of invasion & & & $<0.001^{\mathrm{a}}$ & 1.93 & $0.27-39.5$ & 0.546 \\
\hline $\mathrm{T} 3, \mathrm{~T} 4$ & 56 & 37.4 & & & & \\
\hline $\mathrm{T} 1, \mathrm{~T} 2$ & 14 & 100.0 & & & & \\
\hline Lymph node metastasis & & & $<0.001^{\mathrm{a}}$ & 2.97 & $0.70-16.1$ & 0.145 \\
\hline $\mathrm{N} 2, \mathrm{~N} 3$ & 44 & 32.2 & & & & \\
\hline N0, N1 & 26 & 77.8 & & & & \\
\hline Lymphatic invasion & & & $0.008^{\mathrm{a}}$ & 1.46 & $0.28-6.04$ & 0.629 \\
\hline ly2, ly3 & 54 & 39.7 & & & & \\
\hline ly0, ly1 & 16 & 79.1 & & & & \\
\hline Venous invasion & & & $0.004^{\mathrm{a}}$ & 1.05 & $0.24-3.62$ & 0.948 \\
\hline $\mathrm{v} 1$ & 51 & 39.8 & & & & \\
\hline v0 & 19 & 74.8 & & & & \\
\hline Peritoneal metastasis & & & $<0.001^{\mathrm{a}}$ & 3.00 & $1.30-7.04$ & $0.011^{\mathrm{a}}$ \\
\hline Positive & 17 & 11.8 & & & & \\
\hline Negative & 53 & 60.5 & & & & \\
\hline \multicolumn{7}{|l|}{ Hepatic metastasis } \\
\hline Positive & 0 & - & & & & \\
\hline Negative & 70 & 48.7 & & & & \\
\hline
\end{tabular}

${ }^{\text {a} S t a t i s t i c a l l y ~ s i g n i f i c a n t . ~ M G C, ~ m u c i n o u s ~ g a s t r i c ~ c a r c i n o m a ; ~ N M G C, ~ n o n-M G C ; ~ S D, ~ s t a n d a r d ~ d e v i a t i o n ; ~ C I, ~ c o n f i d e n c e ~ i n t e r v a l . ~}$

MGC patients (Table IV). Of these 7 factors, peritoneal metastasis was determined as a relevant factor by the Cox proportional hazards model (odds ratio, 3.00; $\mathrm{P}=0.011$ ). When all the investigated gastric cancer patients were analyzed, the Cox proportional hazards model revealed that tumor size, macroscopic type, depth of invasion, lymph node metastasis, peritoneal metastasis and hepatic metastasis were significant predictive factors for survival. However, histological type was not an independent prognostic factor (MGC vs. NMGC; odds ratio, $1.41 ; \mathrm{P}=0.062$ ) (Table $\mathrm{V}$ ).

\section{Discussion}

Although gastric carcinoma is one of the most common malignancies, its histological classification remains controversial. The incidence of MGC reportedly varies between 2.6 and $6.6 \%$ (4-8). In our cohort of 2,562 gastric cancer patients, $70 \mathrm{MGC}$ and 2,492 NMGC cases were identified, with a $2.7 \%$ incidence of MGC.

Although a number of previous survival studies have attempted to compare carcinomas with and without mucinous 
Table V. Univariate and multivariate analyses of prognostic factors for all gastric cancer patients.

\begin{tabular}{|c|c|c|c|c|c|c|}
\hline \multirow[b]{2}{*}{ Factors } & \multicolumn{3}{|c|}{ Univariate analysis } & \multicolumn{3}{|c|}{ Multivariate analysis } \\
\hline & $\begin{array}{c}\text { No. } \\
(n=2,562)\end{array}$ & $\begin{array}{c}\text { Disease-free } \\
\text { survival rate }(\%)\end{array}$ & P-value & $\begin{array}{l}\text { Odds } \\
\text { ratio }\end{array}$ & $95 \% \mathrm{CI}$ & P-value \\
\hline Age (years) & & & $0.038^{\mathrm{a}}$ & 1.10 & $0.92-1.30$ & 0.278 \\
\hline$\geq 65$ & 1,443 & 72.6 & & & & \\
\hline$<65$ & 1,119 & 76.8 & & & & \\
\hline Gender & & & 0.711 & & & \\
\hline Male & 1,753 & 50.7 & & & & \\
\hline Female & 809 & 43.8 & & & & \\
\hline Tumor size (mm) & & & $<0.001^{\mathrm{a}}$ & 1.31 & $1.09-1.57$ & $0.004^{\mathrm{a}}$ \\
\hline$\geq 80$ & 576 & 34.2 & & & & \\
\hline$<80$ & 1,986 & 85.8 & & & & \\
\hline Tumor location $(n=2,348)$ & & & 0.988 & & & \\
\hline Lower & 1,096 & 78.9 & & & & \\
\hline Middle, upper & 1,252 & 79.4 & & & & \\
\hline Macroscopic type $(n=993)$ & & & $<0.001^{\mathrm{a}}$ & 1.47 & $1.20-1.80$ & $<0.001^{\mathrm{a}}$ \\
\hline Borrmann 3, 4 & 624 & 30.7 & & & & \\
\hline Borrmann 1, 2 & 369 & 58.8 & & & & \\
\hline Depth of invasion & & & $<0.001^{\mathrm{a}}$ & 3.21 & $1.97-5.68$ & $<0.001^{\mathrm{a}}$ \\
\hline $\mathrm{T} 3, \mathrm{~T} 4$ & 984 & 38.3 & & & & \\
\hline $\mathrm{T} 1, \mathrm{~T} 2$ & 1,578 & 97.1 & & & & \\
\hline Lymph node metastasis & & & $<0.001^{\mathrm{a}}$ & 2.52 & $2.01-3.18$ & $<0.001^{\mathrm{a}}$ \\
\hline $\mathrm{N} 2, \mathrm{~N} 3$ & 680 & 26.5 & & & & \\
\hline N0, N1 & 1,882 & 91.6 & & & & \\
\hline Lymphatic invasion & & & $<0.001^{\mathrm{a}}$ & 1.30 & $0.95-1.81$ & 0.104 \\
\hline ly $2,1 y 3$ & 1,059 & 39.7 & & & & \\
\hline ly0, ly 1 & 1,503 & 79.1 & & & & \\
\hline Venous invasion & & & $<0.001^{\mathrm{a}}$ & 1.03 & $0.84-1.25$ & 0.798 \\
\hline $\mathrm{v} 2, \mathrm{v} 3$ & 293 & 29.2 & & & & \\
\hline $\mathrm{v} 0, \mathrm{v} 1$ & 2,269 & 80.2 & & & & \\
\hline Peritoneal metastasis & & & $<0.001^{\mathrm{a}}$ & 3.06 & $2.49-3.74$ & $<0.001^{\mathrm{a}}$ \\
\hline Positive & 170 & 5.0 & & & & \\
\hline Negative & 2,392 & 79.4 & & & & \\
\hline Hepatic metastasis & & & $<0.001^{\mathrm{a}}$ & 3.45 & $2.56-4.59$ & $<0.001^{\mathrm{a}}$ \\
\hline Positive & 75 & 56.5 & & & & \\
\hline Negative & 2,487 & 76.6 & & & & \\
\hline Histopathological type & & & & 1.41 & $0.98-2.10$ & 0.062 \\
\hline MGC & 70 & 48.7 & $<0.001^{\mathrm{a}}$ & & & \\
\hline NMGC & 2,492 & 75.2 & & & & \\
\hline
\end{tabular}

aStatistically significant. MGC, mucinous gastric carcinoma; NMGC, non-MGC; SD, standard deviation; CI, confidence interval.

characteristics, MGC remains a histological subtype of unclear prognosis. In this study, we investigated various clinicopathological characteristics, including age, gender, tumor location, tumor size, macroscopic type, lymphovascular invasion, peritoneal metastasis, hepatic metastasis and tumor-node-metastasis (TNM) stage. Kunisaki et al (4) and Hyung et al (8) reported no significant differences in tumor size between MGC and NMGC patients. Furthermore,
Zhang et al (6) suggested that tumor size, depth of invasion and lymph node metastasis were not associated with MGC and NMGC. However, we observed that MGC and NMGC differed in tumor size, macroscopic type, lymphovascular invasion, peritoneal metastasis and TNM stage, which was in agreement with the findings of Adachi et al (7) and Yin et al (14).

In this study, only 6 of 70 MGC patients were diagnosed with early-stage disease. Our results also indicated that the 
incidence of early-stage diseases was lower in MGC compared to that in NMGC cases (8.6 vs. 55.1\%). Several previous reports have described the rarity of early-stage gastric cancer. Lim et al (9) reported that the incidence of early-stage MGC was only $6.5 \%$ compared to $26.0 \%$ in NMGC cases, whereas those rates were 20.0 and $44.6 \%$, respectively, in a study by Kunisaki et al (4). Therefore, it is necessary to compare the clinicopathological significance according to disease stage. We also investigated the clinicopathological characteristics of stage III and IV MGC and NMGC cases and found that the two groups did not differ in tumor size, macroscopic type, lymphovascular invasion and TNM stage. Additionally, peritoneal metastasis was more frequently observed in MGC, whereas hepatic metastasis was more common in NMGC cases. The rare incidence of hepatic metastasis in MGC was in accordance with the results reported by Kawamura et al (5).

The presence of a mucinous component is generally associated with poor prognosis in colorectal cancer patients (15). However, such a prognostic correlation is less well defined in MGC. Several studies reported a poor prognosis for MGC patients $(5,9,10)$, while others suggested no significant prognostic differences between MGC and NMGC $(7,11)$. We observed that the 5-year survival rate of MGC patients was worse compared to that of NMGC patients. However, no such significant differences in survival rates were observed between the two groups when the patients were stratified according to their disease stage. Our results were in agreement with those of Yasuda et al (11) and Kawamura et al (5). Furthermore, the multivariate analysis demonstrated that mucinous histological type was not a prognostic indicator in patients with gastric cancer. Thus, our findings suggested that the main factor affecting the poorer prognosis of MGC compared to that of NMGC was the more frequent incidence of advanced-stage disease at diagnosis, rather than the aggressive biological behavior of MGC. However, the reason why MGC is usually diagnosed at an advanced stage remains unclear. Previous studies suggested the following possibilities: (i) MGC is considered to initially arise as a typical adenocarcinoma, which then becomes MGC as the tumor progresses and such a progression may be considered as a dedifferentiation process; (ii) as a tumor invades the gastric wall, the intraluminal excretion of mucin decreases and an increasing deposition of mucin leads to the intramural accumulation; and (iii) MGC is mainly located in the submucosal or deeper layer, which may also be explained by the intramural accumulation of mucin $(7,8,14)$. However, the origin and progression of MGC remain poorly understood.
In conclusion, our results indicated that MGC is rare and mainly detected at an advanced stage, with a poorer overall prognosis compared to that of NMGC. However, the prognosis of MGC according to disease stage was similar to that of NMGC. Therefore, the MGC histological subtype was not found to be an independent prognostic factor of gastric cancer. Further investigation on the origin and progression of MGC is required to advance this field.

\section{References}

1. Parkin DM, Bray FI and Devesa SS: Cancer burden in the year 2000. The global picture. Eur J Cancer 37 (Suppl 8): 4-66, 2001.

2. Santoro R, Carboni F, Lepiane P, Ettorre GM and Santoro E: Clinicopathological features and prognosis of gastric cancer in young European adults. Br J Surg 94: 737-742, 2007.

3. Lee HH, Song KY, Park CH and Jeon HM: Undifferentiated-type gastric adenocarcinoma: prognostic impact of three histological types. World J Surg Oncol 10: 254, 2012.

4. Kunisaki C, Akiyama H, Nomura M, Matsuda G, Otsuka Y Ono HA and Shimada H: Clinicopathologic characteristics and surgical outcomes of mucinous gastric carcinoma. Ann Surg Oncol 13: 836-842, 2006.

5. Kawamura H, Kondo Y, Osawa S, et al: A clinicopathologic study of mucinous adenocarcinoma of the stomach. Gastric Cancer 4: 83-86, 2001.

6. Zhang M, Zhu GY, Zhang HF, Gao HY, Han XF and Xue YW: Clinicopathologic characteristics and prognosis of mucinous gastric carcinoma. J Surg Oncol 102: 64-67, 2010.

7. Adachi Y, Mori M, Kido A, Shimono R, Maehara Y and Sugimachi K: A clinicopathologic study of mucinous gastric carcinoma. Cancer 69: 866-871, 1992.

8. Hyung WJ, Noh SH, Shin DW, Yoo CH, Kim CB, Min JS and Lee KS: Clinicopathologic characteristics of mucinous gastric adenocarcinoma. Yonsei Med J 40: 99-106, 1999.

9. Lim SW, Kim DY, Kim YJ and Kim SK: Clinicopathologic features of mucinous gastric carcinoma. Dig Surg 19: 286-290, 2002.

10. Wu CY, Yeh HZ, Shih RT and Chen GH: A clinicopathologic study of mucinous gastric carcinoma including multivariate analysis. Cancer 83: 1312-1318, 1998.

11. Yasuda K, Shiraishi N, Inomata M, Shiroshita H, Ishikawa K and Kitano S: Clinicopathologic characteristics of early-stage mucinous gastric carcinoma. J Clin Gastroenterol 38: 507-511, 2004.

12. Watanabe H, Jass JR and Sobin LH (eds): Histological typing of oesophageal and gastric tumors: WHO international histological classification of tumors. 2nd edition. Cancer 66: 2162-2167, 1990.

13. Japanese Gastric Cancer Association: Japanese classification of gastric carcinoma: 3rd English edition. Gastric Cancer 14: 101-112, 2011.

14. Yin C, Li D, Sun Z, Zhang T, Xu Y, Wang $\mathrm{Z}$ and $\mathrm{Xu} \mathrm{H}$ : Clinicopathologic features and prognosis analysis of mucinous gastric carcinoma. Med Oncol 29: 864-870, 2012.

15. Sadahiro S, Ohmura T, Saito T and Akatsuka S: An assessment of the mucous component in carcinoma of the colon and rectum. Cancer 64: 1113-1116, 1989. 